\section{Spontaneous fertility in a male thalassemic patient after allogeneic hematopoietic cell transplantation}

\author{
Nicoletta Iacovidou, ${ }^{1}$ Maria Kollia, ${ }^{1}$ \\ Emmeleia Nana, ${ }^{1}$ Theodora Boutsikou, ${ }^{1}$ \\ Christos Savvidis, ${ }^{2}$ Antonis Kattamis, ${ }^{3}$ \\ Dimitra Kyriakopoulou, ${ }^{3}$ Vassilis Ladis ${ }^{3}$ \\ ${ }^{1}$ Department of Neonatology, National \\ and Kapodistrian University of Athens, \\ Aretaieion Hospital; ${ }^{2}$ Department of \\ Endocrinology and Metabolism, \\ Hippocration General Hospital of \\ Athens; ${ }^{3}$ Thalassaemia Unit, Division of \\ Pediatric Hematology-Oncology, First \\ Department of Pediatrics, National and \\ Kapodistrian University of Athens, Agia \\ Sofia Children's Hospital, Athens \\ Greece
}

\begin{abstract}
Patients with thalassemia major who received allogeneic hematopoietic cell transplantation are at increased risk of gonadal insufficiency and reduced fertility due to the toxicity of both the transfusional iron overload and the gonadotoxic effects of drugs used in the conditioning regimen. We present a case of an ex-thalassemic patient with spontaneous recovery of spermatogenesis that fathered a healthy, term male neonate. Maternal hemoglobin electrophoresis was within normal limits. At the age of 9.5 years the patient underwent hematopoietic cell transplantation. The conditioning therapy included busulfan (16 $\mathrm{mg} / \mathrm{kg})$ and cyclophosphamide (200 $\mathrm{mg} / \mathrm{kg}$ ). No irradiation was administered. Thirty-two days after the hematopoietic cell transplantation the patient developed acute graft-versus-host disease needing long-term treatment with methylprednisolone, cyclosporine and immunoglobulin. Although consecutive semen analyses after the hematopoietic cell transplantation revealed azoospermia, the last semen analysis before conception, at the age of 33 years, was improved and normal follicle stimulating hormone (FSH), luteinizing hormone (LH) and testosterone (Te) levels were detected. The current pregnancy was the result of physical conception. In this case, it seems that thalassemia major along with the respective treatment prior to- and posthematopoietic cell transplantation did not irreparably impair spermatogenesis, probably due to the pre-pubertal time frame they were implemented.
\end{abstract}

\section{Introduction}

Regular transfusions and intensive chelation therapy for patients with thalassemia major have increased their life span well into late adulthood and improved their quality of life. ${ }^{1}$ As a result, their expectation for reproduction has also increased. However, endocrine complications due to hemosiderosis and especially hypogonadotrophic hypogonadism are still present leading to dysfunction of the reproductive system in a considerable number of patients. Although reports of successful pregnancies in female patients, either spontaneous or after induction of ovulation, have been adequately presented, fatherhood in male patients is considered relatively rare. ${ }^{2}$ Etiology of impaired male fertility is multifactorial including hypogonadism, sperm abnormalities, and complications of additional medical therapies.

Pregnancies in female patients with thalassemia major, as well as fatherhood in male patients who had allogeneic hematopoietic cell transplantation have been reported only occasionally. ${ }^{3}$ These patients are at increased risk of gonadal insufficiency and reduced fertility, not only because of the effects of transfusional iron overload, but also because of the gonadotoxic effects of drugs used in the conditioning regimen. ${ }^{4}$ We report a case of a Greek 33-year-old male with history of thalassemia major and a successful allogeneic hematopoietic cell transplantation that has fathered a healthy offspring, following physical conception.

\section{Case Report}

The 33-year-old father had a history of thalassemia major (genotype: IVSI110/IVSI-110) diagnosed at the age of 15 months. Subsequently to diagnosis, he was treated with regular transfusions every 1417 days maintaining hematocrit levels between $28-30 \%$. Additionally, he received chelation with subcutaneous infusions of desferrioxamine (DFO) at a dose of 1.5-2 g/day, 5 days per week. His ferritin levels ranged around $2000 \mathrm{ng} / \mathrm{ml}$. No signs of extramedular hemopoiesis, skeletal malformations, or other clinical pathology were detected. His growth was otherwise normal.

At the age of 9.5 years the patient underwent matched related hematopoietic cell transplantation, with his younger sister being the donor. The conditioning therapy included busulfan $(16 \mathrm{mg} / \mathrm{kg})$ and cyclophosphamide (200 mg/kg). Low dose methylprednisolone and Cyclosporine were
Correspondence: Vassilis Ladis, Thalassemia Unit, Division of Pediatric HematologyOncology, First Department of Pediatrics, National and Kapodistrian University of Athens, Agia Sofia Children's Hospital, Athens Greece, Papadiamantopoulou and Levadias Str., Goudi 11527, Athens, Greece. E-mail: vassilisladis@gmail.com

Key words: Thalassemia; allogeneic hematopoietic cell transplantation; male fertility.

Contributions: the authors contributed equally.

Conflict of interest: the authors declare no conflict of interest.

Received for publication: 21 September 2017. Revision received: 11 October 2017.

Accepted for publication: 20 October 2017.

This work is licensed under a Creative Commons Attribution 4.0 License (by-nc 4.0).

(C) Copyright N. Iacovidou et al., 2017

Licensee PAGEPress, Italy

Thalassemia Reports 2017; 7:7090

doi:10.4081/thal.2017.7090

given for graft-versus-host disease prophylaxis. No irradiation was administered. Thirty-two days after the hematopoietic cell transplantation the patient developed acute graft-versus-host disease with prominent symptoms from the gastrointestinal tract (diarrhea), respiratory system (emphysema) and skin. The patient required long term treatment, nearly for four years, with methylprednisolone, cyclosporine, immunoglobulin and co-trimoxazole. During that period, he developed insulin dependent hyperglycemia, which was restored soon after drug discontinuation. Mild skin chronic graft-versus-host disease activity resolved ten years after the hematopoietic cell transplantation. Today patient preserves a complete allogeneic engraftment, maintaining a hematocrit $>30 \%$ and hemoglobin around $13 \mathrm{~g} / \mathrm{dL}$. His ferritin dropped gradually to normal levels. Low bone density was detected at the age of 27 years.

Consecutive semen analyses post hematopoietic cell transplantation at 17 and 18 years of age revealed azoospermia, a finding attributed to the toxicity related to his previous medical history. The development of external genitalia and basal gonadotropin and testosterone levels were normal, but the luteinizing hormone-releasing hormone (LH-RH) test revealed a poor response of follicle stimulating hormone (Tables 1 and 2). 
Table 1. Hormone profile and semen analysis.

\begin{tabular}{|c|c|c|c|c|c|c|}
\hline \multirow[t]{2}{*}{ Hormone profile } & \multicolumn{4}{|c|}{ Age (years) } & \multirow[t]{2}{*}{8 months after conception } & \multirow[t]{2}{*}{ Normal values } \\
\hline & 17 & 18 & 20 & 33 & & \\
\hline FSH & 3.23 & 2.66 & 3.00 & 2.17 & 3.03 & $0.7-11.1 \mathrm{mU} / \mathrm{mL}$ \\
\hline $\mathrm{LH}$ & 2.45 & 1.80 & 4.2 & 2.3 & 2.47 & $0.8-7.6 \mathrm{mU} / \mathrm{mL}$ \\
\hline Testosterone & 6.00 & 5.90 & 9.00 & 4.64 & 4.61 & $2.86-15.1 \mathrm{ng} / \mathrm{mL}$ \\
\hline SHBG & - & - & - & 29.2 & 30.2 & $13-71 \mathrm{mU} / \mathrm{mL}$ \\
\hline TSH & 1.03 & - & 0.98 & 0.966 & 0.58 & $0.25-4.5 \mathrm{IU} / \mathrm{mL}$ \\
\hline T3 & 1.2 & - & 1.02 & 1.8 & 1.43 & $0.8-2.2 \mathrm{nmol} / \mathrm{L}$ \\
\hline FT4 & - & - & - & 1.65 & 1.27 & $0.8-1.76 \mathrm{ng} / \mathrm{dL}$ \\
\hline PRL & 35 & 36 & 30 & 45 & - & $1.5-16 \mathrm{ng} / \mathrm{mL}$ \\
\hline \multicolumn{7}{|c|}{ Semen analysis } \\
\hline Total volume & 8 & 5 & - & 2.5 & $5 \mathrm{~mL}$ & $\geq 2.5 \mathrm{~mL}$ \\
\hline Sperm count & 0 & 0 & - & $6.25 \times 10^{6}$ & $22.5 \times 10^{6}$ & $40-300 \times 10^{6}$ \\
\hline Sperm count/mL & 0 & 0 & - & $2.5 \times 10^{6}$ & $4.5 \times 10^{6}$ & $\geq 20 \times 10^{6} / \mathrm{mL}$ \\
\hline $\mathrm{pH}$ & 7.5 & 7.7 & - & 8 & 7.8 & 7.1-8.0 \\
\hline Motility & - & - & - & $45 \%$ & $60 \%$ & $\geq 50 \%$ \\
\hline Morphology-normal & - & - & - & $70 \%$ & $65 \%$ & $\geq 30 \%$ \\
\hline Liquefaction & 30 & 30 & - & 30 & . & $\leq 20 \mathrm{~min}$ \\
\hline
\end{tabular}

FSH, follicle stimulating hormone; LH, luteinizing hormone; SHBG, sex hormone-binding globulin; TSH, thyroid-stimulating hormone; T3, triiodothyronine; FT4, free thyroxine; PRL, prolactin.

Twenty-three years after the hematopoietic cell transplantation the patient became father with physical methods. A few months prior to conception the pituitary hormones (FSH, LH) and the testosterone basal levels were normal (Table 1). Semen analysis showed severe oligospermia (2.5 million sperm $/ \mathrm{mL}$ ) but improved when compared with prior tests; motility at $2 \mathrm{~h}$ was sufficient, and morphology was normal. Pituitary MRI was performed due to hyperprolactinemia, demonstrating no enhancement of pituitary adenoma or any other pathology. Mother a primigravida primipara 24-year-old healthy woman had an uneventful pregnancy. Maternal hemoglobin electrophoresis, as part of her antenatal care revealed $\mathrm{HbA}_{2} 2.9 \%$ and $\mathrm{HbF}<0.1 \%$ (within normal limits). Because of the paternal medical history, prenatal diagnosis was suggested (for possible mutations of hemoglobin's genes), which was not accepted due to religious reasons.

The offspring, a term male neonate (gestational age of $39+1 \mathrm{w}$ ), was born by lower segment cesarean section due to failure to progress. Apgar score was 9 at $1 \mathrm{~min}$ and 10 at $5 \mathrm{~min}$. Birth weight was $3350 \mathrm{~g}$ corresponding to the $70^{\text {th }}$ customized centile (WHO Child Growth Standards). Clinical examination was normal and no stigmata of congenital malformations were present.

\section{Discussion}

Thalassemia major is a severe transfu- sion-dependent anemia requiring treatment with regular red blood cells transfusions, iron chelation and supplementary treatment of secondary complications, most commonly attributed to iron overload. ${ }^{5}$ Hematopoietic cell transplantation from a related or unrelated HLA identical donor is the only curative treatment currently available for these patients. ${ }^{3}$

Endocrine abnormalities are among the most common complications of thalassemia major. In a multicenter study, hypogonadism, being the most frequent endocrinopathy, affected $40.5 \%$ of patients. ${ }^{6}$ Several other studies show that fertility is more compromised in male transfusion-dependent thalassemia major patients, with oligospermia and asthenospermia being present in $53 \%$. $^{2,7}$

Infertility in thalassemia major is mainly attributed to iron accumulation in the pituitary gland, which is toxic for the gonadotropin secreting cells leading to hypogonadotrophic hypogonadism. ${ }^{8-10}$ The anterior pituitary gland is particularly sensitive to free radicals produced by oxidative stress, which further contributes to male infertility through increased production of reactive oxygen species (ROS) that may further damage the sperm membrane, nucleus, and proteins..$^{9,11}$ Moreover, hypoxemia, present in transfusion dependent thalassemia major patients, further damages germinal epithelium of testes; adverse effects on testes and sperm can last for several weeks or even months, mainly depending on the degree and duration of hypoxemia. ${ }^{12}$
Table 2. Poor response of FSH during LHRH test.

\begin{tabular}{lcc}
\hline Time $(\mathrm{sec})$ & $\begin{array}{c}\mathrm{LH} \\
(\mathrm{m} / \mathrm{U} / \mathrm{mL})\end{array}$ & $\begin{array}{c}\text { FSH } \\
(\mathrm{m} / \mathrm{U} / \mathrm{mL})\end{array}$ \\
\hline $0^{\prime}$ & 0.50 & 0.90 \\
$20^{\prime}$ & 6.10 & 0.60 \\
\hline $40^{\circ}$ & 7.00 & 0.80 \\
$60^{\circ}$ & 6.40 & 0.80 \\
\hline $120^{\prime}$ & 4.00 & 0.90 \\
\hline
\end{tabular}

FSH, follicle stimulating hormone; LH, luteinizing hormone; LH-RH, luteinizing hormone-releasing hormone.

Even though our patient received regular transfusions and effective chelation treatment, the relative hypoxemia and oxidative stress due to free iron, are considered the initial contributors to his infertility. Additionally, fertility was further challenged with hematopoietic cell transplantation conditioning therapy, acting on germ cells during spermatogenesis and leading to prolonged or even permanent azoospermia. The extent of damage is dependent on the age of the patient, the agent administered, the dose delivered, the combination of cytotoxic drugs and the potential synergic interaction of radiotherapy if used. ${ }^{13}$

Since both alkylating agents and irradiation are mutagenic with the potential of injury to germ cell chromosomes, children born to patients who recover gonadal function may be at increased risk for development of genetic diseases and congenital anomalies. ${ }^{14}$ In this respect, close pediatric evaluation and possibly genetic consultation for the offspring are required.

Spermatogenesis recovers in approxi- 
mately $80 \%$ of male patients within a minimum of 5 years after busulfan and cyclophosphamide treatment. ${ }^{15}$ In one study, patients given cyclophosphamide combined with busulfan presented initial sperm recovery after 3 years and $50 \%$ of them had sperm in the ejaculate after 7 years. Therefore, recovery after hematopoietic cell transplantation may be underestimated if sperm samples are evaluated too early. ${ }^{16}$ Borgmann-Staudt et al. reported that at a median of 6 years after hematopoietic cell transplantation, $31 \%$ of males seemed to be fertile. Three male participants in this group had thalassemia major. Analyzing fertility separately for malignant and nonmalignant diseases, they found that fertile patients were $21 \%$ and $42 \%$ in these groups respectively. ${ }^{17}$ Normal serum levels of follicle stimulating hormone and spermatozoa were detected in semen samples, suggesting that progressive recovery of spermatogenesis is possible after busulfan-based conditioning for hematopoietic cell transplantation in childhood. Younger age was reported to be associated with an increased likelihood of fertility recovery. ${ }^{18-21}$ Only one study reported that pre-pubertal therapy in males increased the risk for infertility, which is inconsistent with findings of other recent studies. ${ }^{17}$ Furthermore, recipients with prolonged chronic graft-versus-host disease had a significant trend for lower sperm counts thus enhancing infertility. ${ }^{22}$ On the contrary, the absence of chronic graft-versus-host disease was associated with a higher incidence of spermatogenesis. $^{21}$

Our thalassemia major patient was subjected to hematopoietic cell transplantation at the age of 9.5 years and suffered from acute graft-versus-host disease, followed by mild chronic graft-versus-host disease. Luteinizing hormone levels were normal suggesting that Leydig cells were not damaged in such extend to cause testosterone deficiency. In addition, semen analyses at the age of 17 and 18 years showed azoospermia with normal follicle stimulating hormone levels. However, follicle stimulating hormone response after luteinizing hormone-releasing hormone stimulation was not normal suggesting some degree of secondary hypogonadism. More recent semen analysis that has been done soon before and after conception indicates gradual improvement of spermatogenesis.

\section{Conclusions}

We present a case of physical conception and delivery of an apparently healthy baby, from a couple where the father was an ex- thalassemia major patient. He had been properly treated with regular transfusions and chelation therapy, followed by hematopoietic cell transplantation early in childhood. The nature of his disease, and the respective treatments prior to- and posthematopoietic cell transplantation, seemed to be the contributors to his transient infertility. Although there was no DNA test to confirm the paternity of the neonate, a more recent normal semen analysis, eight months after conception, definitively confirms recovery of fertility. Nevertheless, it seems that the above medications and treatment complications did not impair spermatogenesis permanently, probably due to the prepubertal time frame they were implemented, a finding that is consistent with the current literature. Finally, for the ex-thalassemic, post-hematopoietic cell transplantation patient, the need for appropriate genetic counseling and genotyping should be emphasized for thalassemia prevention strategy. It should be noted that hematopoietic cell transplantation does not reverse the genetic defect but it is a treatment option for thalassemia major that offers effective control of clinical symptoms.

\section{References}

1. Ladis V, Chouliaras G, Berdoukas V, et al. Survival in a large cohort of Greek patients with transfusion-dependent beta thalassaemia and mortality ratios compared to the general population. Eur J Haematol 2011;86:332-8.

2. Skordis N, Petrikkos L, Toumba M, et al. Update on fertility in thalassaemia major. Pediatr Endocrinol Rev 2004;2:296-302.

3. Angelucci E, Baronciani D. Allogeneic stem cell transplantation for thalassemia major. Haematologica 2008;93:1780 LP-1784.

4. Santarone S, Natale A, Olioso P, et al. Pregnancy outcome following hematopoietic cell transplantation for thalassemia major. Bone Marrow Transpl 2017;52:388-93.

5. Kattamis C, Ladis V. Conventional treatment of $\beta$-thalassemia syndromes: a personal experience. Int J Pediatr Hematol Oncol 1997;4:513-22.

6. De Sanctis V, Eleftheriou A, Malaventura C; Thalassaemia International Federation Study Group on Growth and Endocrine Complications in Thalassaemia. Prevalence of endocrine complications and short stature in patients with thalassaemia major: a multicenter study by the Thalassaemia International
Federation (TIF). Pediatr Endocrinol Rev 2004;2:249-55.

7. Vullo C, De Sanctis V, Katz M, et al. Endocrine abnormalities in thalassemia. Ann NY Acad Sci 1990;612:293-310.

8. Safarinejad MR. Evaluation of semen quality, endocrine profile and hypothalamus-pituitary-testis axis in male patients with homozygous $\beta$-thalassemia major. J Urol 2008;179:232732.

9. Singer ST, Killilea DW, Suh JH, et al. Fertility in transfusion-dependent thalassemia men: Effects of iron burden on the reproductive axis. Am J Hematol 2015;90:E190-2.

10. Bajoria R, Chatterjee R. Hypogonadotrophic hypogonadism and diminished gonadal reserve accounts for dysfunctional gametogenesis in thalassaemia patients with iron overload presenting with infertility. Hemoglobin 2011;35:636-42.

11. De Sanctis V, Soliman AT, Elsedfy H. Late-onset male hypogonadism and fertility potential in thalassemia major patients: two emerging issues. Mediterr J Hematol Infect Dis 2015;7:e2015047.

12. Bomhard EM, Gelbke H-P. Hypoxaemia affects male reproduction: a case study of how to differentiate between primary and secondary hypoxic testicular toxicity due to chemical exposure. Arch Toxicol 2013;87:120118.

13. Wyns C. Male fertility preservation before gonadotoxic therapies. Facts, Views Vis Ob Gyn 2010;2:88-108.

14. Sanders JE, Hawley J, Levy W, et al. Pregnancies following high-dose cyclophosphamide with or without high-dose busulfan or total-body irradiation and bone marrow transplantation. Blood 1996;87:3045-52.

15. Panasiuk A, Nussey S, Veys $P$, et al. Gonadal function and fertility after stem cell transplantation in childhood: Comparison of a reduced intensity conditioning regimen containing melphalan with a myeloablative regimen containing busulfan. $\mathrm{Br} \mathrm{J}$ Haematol 2015;170:719-26.

16. Anserini P, Chiodi S, Spinelli S, et al. Semen analysis following allogeneic bone marrow transplantation. Additional data for evidence-based counselling. Bone Marrow Transplant 2002;30:447-51.

17. Borgmann-Staudt A, Rendtorff R, Reinmuth $\mathrm{S}$, et al. Fertility after allogeneic haematopoietic stem cell transplantation in childhood and adolescence. Bone Marrow Transplant 2012;47:271-6. 
18. Wilhelmsson M, Vatanen A, Borgström $\mathrm{B}$, et al. Adult testicular volume predicts spermatogenetic recovery after allogeneic HSCT in childhood and adolescence. Pediatr Blood Cancer 2014;61:1094-100.

19. Mertens AC, Ramsay NKC, Kouris S, Neglia JP. Patterns of gonadal dysfunction following bone marrow transplantation. Bone Marrow Transplant 1998;22:345-50.
20. Pfitzer C, Orawa H, Balcerek M, et al. Dynamics of fertility impairment and recovery after allogeneic haematopoietic stem cell transplantation in childhood and adolescence: results from a longitudinal study. J Cancer Res Clin Oncol 2015;141:135-42.

21. Rovó A, Tichelli A, Passweg JR, et al. Spermatogenesis in long-term survivors after allogeneic hematopoietic stem cell transplantation is associated with age, time interval since transplantation, and apparently absence of chronic GvHD. Blood 2006;108.

22. Grigg AP, McLachlan R, Zajac J, Szer J. Reproductive status in long-term bone marrow transplant survivors receiving busulfan-cyclophosphamide $\mathrm{mg} / \mathrm{kg}$ ). Bone Marrow Transplant 2000;26:1089-95. 